Nov, 1st. - A slight blue line on the gums.

4th. - Complains of loss of appetite, and has frequent calls to stool ; the bowels, however, do not act.

5th.-Ordered five grains of acetate of lead and one grain of opium powder three times a day.

18th. - He complains of loss of appetite. His condition is much the same as on the 4th. Ordered an ounce of castor oil immediately.

24th. - The swelling in the popliteal space has been gradually hardening and enlarging, apparently owing to the deposit of fibrin within the sac of the aneurism.

26th. - Ordered two drachms of castor oil immediately.

Dec. 2nd.-Is obliged to discontinue taking the pills on account of the colic produced. The pulsation in the tumour is very much less.

3rd.-Feels easier; has less pain in stomach. Ordered the magnesia and salts mixture twice a day.

5th. - Slept badly, having pain in his stomach; his appetite has much diminished.

12th.-The pulsation has ceased, but the tumour is larger and more tender, and he cannot straighten his leg on account of the mechanical obstruction caused by it.

15th. - Mr. Hilton found that by pressing the femoral artery he could affect the sac, but thought the aneurism was almost cured. The patient has now a clear, well-defined blue line on the margins of the gums, and feels no pain in the stomach. The articular arteries of the left knee-joint can be seen pulsating very distinctly.

17th.-The tumour, which almost fills the popliteal space, is diminishing in size. He can nearly straighten his leg. The left leg is flabby, and swells if he stands much upon it, and it measures two inches more in circumference than the right.

20th. - The tumour is fast diminishing in size.

31st.-. fie has left the hospital to return to his work.

On Jan. 17th he came to the hospital to be examined by the surgeons, and was seen by nearly the whole surgical staff, amongst the rest by Messrs. Cock, Hilton, and Birkett. He was considered to be perfectly cured. He states that he cannot walk far without feeling a numb sensation over the calf of his left leg, circulation by anastomosing branches being not yet freely established. He has been able to do his work. There is still a clear, well-defined blue line on the margin of the lower gum; the upper is less affected. There is also some enlargement in the popliteal space, which he feels somewhat inconveniently when walking.

It will be observed that the doses of lead were large and continued. Thus three grains of the acetate were given three times a day for six days, and then an increase was made to five grains, a grain of opiam being given with each dose. This five-grain dose was contmued for twenty-six days. With regard to the pains in the abdomen, they never amounted to colic, and my surprise is that the patient did not suffer more. His attention was directed to the probable occurrence of such pains, and latterly he was inclined to exaggerate them. Though rest was enjoined, the patient would not submit to it. He walked about the ward as it pleased him, and, I am informed, danced on one occrsion for the amusement of his companions. It is worthy of remark that when the lead had been taken for three weeks the aneurism had hardened very obviously, 2 , ef my belief is that we might be content to discontinue the sead should an aneurism begin to change as above describe i. The system is charged with the metal, and deposit once begun, we may fairly expect it will continue to the filling up of the sac.

It may be well to mention that the only other case of aneurism in which I have exhibited lead was in that of a man the subject of so advanced a stage of thoracic aneurism that spinal absorption had occurred and paraplegia had been produced. The tumour was clearly visible on the left side of the spine. The case was obviously hopeless, but I gave the lead, in order, if possible, to ascertain what effect it might produce on the structure of the fibrin in the sac on post-mortem examination. The man, however, left the hospital, and, I hear, died shortly afterwards.

Albemarle-street, February 26 th, 1865.

Prussic Acid is Kirschwasser.-MT. Boudet, an able French chemist, has found that good Kirschwasser contains one-fifth of a grain of prussic acid in about three ounces and a half. Bad Kirsche contains four times more. Hence the danger of the latter beverage. M. Boudet, or his commentator, in the Gazette Hebdomadaire of Paris, gives excellent advice on this subject, and begs people to aroid the above. mentioned danger by not drinking any Kirsch at all.

\section{THE PECULIAR APPLICABILITY OF LITHOTRITY TO CASES OF SO-CALLED "PARALISED BLADDER."}

\author{
BI HENRY THOMPSON, F.R.C.S., \\ SERGEOY EXTR IORDTYART TO E.M. THE KTXG OF THE BELGIAYS, \\ SURGEuX TO LNIVERSITY COLIEGE HOSPITAL.
}

I TRUST it has been shown that lithotrity is applicalle to a large number of calculous patients; not only to those who are subjects of a small concretion, but to those who may have stones in the bladder of hard texture and considerable size. But there are several morbid or unusual conditions of the urinary organs, apart from the size and texture of the stone, which it was formerly the custom to regard as contra-indicating the performance of lithotrity, all of which it is certainly not now necessary to consider in that light. Among them is that affection in which the patient has lost the power of passing any urine whatever by the natural efforts, and is compelled to remove it several times daily by means of the catheter. This condition has been usually termed, although not very happily or accurately, "paralysis of the bladder." For in most instances the loss of power to pass the urine naturally is due, not to any impairment whatever of the nervous supply to the organ, but entirely to obstructive disease of the urethra, such as prostatic enlargement, impeling the action of an otherwise healthy bladder. In some cases, again, it may be due to loss of contractile power in the muscular coat of the bladder, produced by some accidental, perhaps voluntary, over-distensionin other words, to atony of that viscus; no obstruction existing in the course of the urethra. And, lastly, these conditions may co-exist to a greater or less extent in any given case.

I have for some time been led to regard such a condition of the bladder not merely as one in which lithotrity ought not to be performed, or might be performed with difficulty; but, on the contrary, as one which is peculiarly favourable to the success of the operation. I have no hesitation in regarding it as presenting circumstances more likely to conduce to a happy result than those which are presented by the ordinary or average run of calculous patients in midrile life who have perfect command of the urinary functions. Nevertheless, examples of success in the cases referred to are stili sometimes spoken of as unusual or exceptional instances. I ventured to express the opinion given above in the Lettsomian lectures of $18 \mathbf{b}^{2}$, and I am no less convinced of its correctness now. The reason seems to be this, that in cases of patients who have been compelled to use their catheters several times daily for some months or years, the passages have become so accustomed to instruments that the pulverized débris may be withdrawn by the lithotrite with comparative impunity; and in these $I$ do not hesitate to alo so, still avoiding the removal of fragments which would irritate the urethra and occasion bleeding. I have operated on several such cases, and have had none that gave less trouble or made better recoveries. It is rare for such patients to suffer from rigor or other constitutional disturbance, for the passages are callous to those sources of irritation which in the patient of ordinary susceptibilities, and unaccustomed to the employment of any instrument in the urethra or bladder, so often arouse systemic derangements of a serious nature.

I believe that it is an error to regard the small calculus recently descended from the kidney into the bladder of an apparently healthy middle-aged man as a matter of very slight gravity and of small surgical importance. I have occasionally seen more distressing and prolonged illness arise from the crushing of such a stone--although only one short and easy sitting sufficed to readily accomplish the object-than from stones of ten times the size. The rery presence of a stone in the bladder for a few months, irritating as it is, seems sometimes to render the bladder accustomed to mechanical contact; and the lithotrite may sometimes be used more safely in such circumstances than in a bladder which has but recently become tenanted by a stone, or which has never been entered by a catheter or sound. The cases of small and recent calculus are those which, perhaps as much as any, benefit prospectively by passing bougies a few times preparatory to the subsequent use of the lithotrite. With all the usual precautions the case of small cr'culus becomes one cf extremely favouralle augury; 
but it is hazardous to be in the least degree indifferent to precautions because the calculus is small or recent.

I have operated in seven cases in which the patients had for years depended on the catheter to evacuate the bladder : in one instance from real spinal paralysis ; in the other six, from atony of the bladder or from enlarged prostate. One only ever had rigors; all made excellent recoveries.

Wimpole-street, March, 1865.

\section{THE}

\section{TOPICAL USE OF SILVER SOLUTIONS.}

By HENRY G. WRIGHT, M.D., M.R.C.P.L., PHYgICIAN TO THE SAMAAITAY HOSPITAL TOR WOMEN.

MY attention has been directed by Dr. Gibb to a note in the correspondents' page of 'THE LANCET of last week (p. 278) inquiring the composition of a solution mentioned by him as containing iodide of silver. In some cases which fell under the conjoint care of my friend Dr. Gibb and myself, I suggested to him a trial of this preparation. At his wish, and as a matter of professional duty, I forward a brief account of the solution referred to-its preparation, properties, and uses.

It is now upwards of five years since my attention was, almost accidentally, directed to its peculiar value as a topical application. Having to treat a number of those common affections of the uterine cervix where a portion of the surface, varying in extent, is denuded of its proper smooth membrane and presents a granular aspect, I was led to carefully observe the comparative influence of various local applications authoritatively recommended for bringing about that restoration of healthy surface which certainly forms a part of the treatment of such cases; although the investigation and removal of those causes, local or constitutional, which originally led to or are liable to induce a recurrence of the mischief, is of more essential importance for the thorough cure.*

I was led to prefer solutions of nitrate of silver of various strength instead of the solid salt so generally employed in these cases, and which exercises but a limited influence; for its caustic or cathæretic action extends only to the parts it touches, on which is soon produced an insoluble and inenergetic white film. This consists of chloride of silver, and of that undetermined compound which the salt forms with albumen. Whatever the principles guiding its application (and there can be no doubt of its value), they differ widely from those which led Higginbotham to advocate its use. He laid especial stress on the endurance of the eschar, which in uterine cases is of course very rapidly loosened and removed. There is, however, probably some degree of insterstitial absorption of the dissolved salt in that period which elapses before the soluble nitrate is all converted into the insoluble chloride.

In treating a case of the kind referred to (where the granular appearance extended to the breadth of a shilling, surrounding the os uteri), I chanced to upset the silver solution (half a drachm to one ounce) previously used, and on the emergency resorted to another preparation of about the same strength, but which had been laid aside as no longer available for its original purpose. It was, in fact, an old photographic nitratebath, still bright and clear, but which had been so long wrorked that it had become saturated with iodide of silver, and contained a considerable amount of ether.

This condition cannot, so far as I know, be extemporaneously produced, otherwise than by the series of changes effected when a number of glass plates coated with iodized collodion are successively dipped into a silver bath. There are several ready solvents of iodide of silver, and solutions of the nitrate will dissolve a small proportion, the quantity varying with the strength of the solution used; but there appears also to be a small additional quantity taken up when large surfaces saturated with iodide are exposed in succession to the action of the solution. Practically, each "dipping" occupies several minutes, until the ether of the collodion has all been absorbed

* "On a malheureusement la facheuse habitude de chercher localement les causes des aftections locales. Or, à notre sens, rien n'est moins rationnel. L'état général de l'économie, sa déviation fonctionelle, sont, dans l'immense majorité des cas, le point de départ de telle ou telle affection bornée à un by the fluid of the bath and the surface appears smooth. The quantity of ether in an old bath is very considerable.

Such, then, was the composition of the solution employed, and to which Dr. Gibb referred. Its beneficial effect was so marked when next I saw the patient that I continued its use, and have employed it largely in similar affections, as well as in other cases suitable for its application: always with the most satisfactory results in determining or expediting the healing process. In other hands it is reported to me as being equally efficacious. An extended use of it in the large number of cases of affections of the throat and larynx which fall under the care of Dr. Gibb has, so he tells me, confirmed his original opinion as to its special advantages over other solutions of silver.

The rationale of its action $I$ take to be as follows:--A reparative process is a healthy process, but one requiring local determination for supplying the new material. This is effected in a roundabout way when an eschar is produced by application of caustic. The textural destruction leads to an energetic blood-supply for repairing the damage, and the originally unsound tendency is overcome by inducing that same reparative process whereby the integrity of healthy tissue is renewed. A fluid application is absorbed into the tissues just where its special influence has to be exercised. This is the case where the solution of the nitrate and iodide are employed; the action being increased by that local capillary determination which the stimulative influence of the ether exercises. The slight smarting sensation soon passes away.

Besides the class of cases alluded to, I have advantageously used this solution in numerous other instances: in relaxed and ulcerated throat, for aphthous patehes, in indolent strumous sores, in eczema aurium, psoriasis palmaris, and erysipelas ; whilst in some cases of chronic ulcer, not, of course, falling under my personal treatment, it has been reported as exercising a marked beneficial influence.

I have fulfilled my purpose of describing the composition of this particular application, and at the same time suggesting a more general use of solutions of nitrate of silver in place of the solid caustic. But it should be borne in mind that all preparations of silver, and notably those containing any proportion of. iodide, are exceedingly liable to be deteriorated by the presence of organic matter, of which the merest trace will arrest or impair the delicate chemical process on which photography depends. It is therefore important to avoid dipping the brush or other vehicle into the bottle of solution. A little should be poured out into a clean watch-glass, and the remnant thrown away. Any respectable photographer will supply the old bath solution described, for he thereby saves the cost of reducing and refining the silver. In one class of cases the influence of this topical application has been so especially marked that $I$ add brief reports of three instances where it was employed. I have selected them as fairly testing its usefulness.

CASE 1.-A lady of healthy appearance, aged forty, who had for two years suffered from a condition of the mucous membrane of the mouth which really embittered her existence. The edges of the tongue and inside of the lips and cheeks presented patches of raw surface, denuded of mucous membrane, and very irritable. Any warm food, anything containing spice or pepper, any stimulant or hard substance, produced. intense burning pain; whilst, night and day, there was a constant dribbling of saliva from the mouth. The general health was good, with no story of any other symptoms of a specific kind. Her husband had been infected before marriage. He believed himself to have been thoroughly cured, but there had been occasional subsequent eruptions. The patient brought me a sheaf of prescriptions. Among them were two for solutions of nitrate of silver, which, as well as the solid caustic, had been freely applied, with but slight benefit. The preparation $I$ have described gave relief on its first application. In a week the abrasions were entirely healed, and she could bite a crust or relish a curry; and the salivation entirely ceased. No constitutional treatment was commenced until the mouth was well, and there has been no relapse in the three years which have intervened.

CASE 2.-A woman, aged thirty-eight, who had been directly infected by her husband some years previously, the local disease being judiciously treated at the time. When she came under notice she was suffering from indurated nodular enlargements of the tongue, of slow growth; conveying that sensation which has been whimsically compared to the feeling of a bag of nuts. The margins were sore, from the pressure of the edges of the teeth. The surface was daily painted with the solution, the woman patiently protruding her tongue until the fiuid was absorbed. The organ gradually diminished to its natural di- 